\title{
Paraplegia
}

\section{Case Report: Hip Joint Instability in an Infant with Paraplegia Following Aortic Surgery}

\author{
N. Suzuki, MD, ${ }^{1} M$. Ando, $M D,{ }^{2}$ E. Gotoh, $\mathbf{M D}^{2}$ \\ ${ }^{1}$ Department of Orthopaedic Surgery, Asahikawa Children's Rehabilitation Center, \\ Shunkodai 2-1, Asahikawa 071, ${ }^{2}$ Department of Orthopaedic Surgery, Asahikawa \\ Medical College, Nishikagura 4-5, 3-11, Asahikawa 078, Hokkaido, Fapan.
}

\section{Summary}

A report on an infant with paraplegia following aortic surgery who suffered from coarctation of the aorta and a ventricular septum defect (VSD). The spinal paralysis was complete and flaccid. He was found to have paralytic bilateral dislocatable hip joints. Magnetic resonance image (MRI) of spinal cord showed no pathological findings. The hip joints were treated by a hip abduction brace.

Key words: Paraplegia; Ischaemic myelopathy; Aortic disease; Hip dislocation.

Paraplegia is a serious complication of surgery for coarctation of the aorta. Its incidence of occurrence is below 1\% (Brewer et al., 1972; Pennington et al., 1979). The non-septic hip instability in patients with spinal cord injuries is uncommon (Baird et al., 1986). We are reporting on a patient with paralytic bilateral dislocatable hip joints in ischaemic myelopathy following surgery for coarctation of the aorta.

\section{Case report}

A 2-year, 8-month-old boy was admitted to the Asahikawa Children's Rehabilitation Center having become paraplegic when he was 1 year, 3 months old. He was born with coarctation of the aorta and a VSD. Surgery for coarctation of the aorta was carried out when he was 11 months old, and paraplegia was found soon after the surgery. It was thought that ischaemic myelopathy had occurred as a complication of aortic surgery. He has not recovered from the neurological disturbance.

When he was first examined at the Asahikawa Children's Rehabilitation Center, there was complete flaccid paralysis below T12 level, including loss of sensation, diminished patellar and Achilles tendon reflex, and no pathological reflexes such as the Babinski reflex. The muscles of the lower extremities were markedly hypotonic. Flexion contractures were present in both hips. The hip joints were easily dislocated by passive adduction and extension of the hip joints. But, they were also easily reduced by passive abduction and flexion (Fig. 1). MRI of the spinal cord did not show any abnormal findings.

In order to treat the dislocatable hip joints, and to maintain these joints in reduction, a hip abduction brace was used (Fig. 2). This brace did not permit passive hip adduction, and extension, but did allow passive hip abduction and flexion. Although he could crawl 

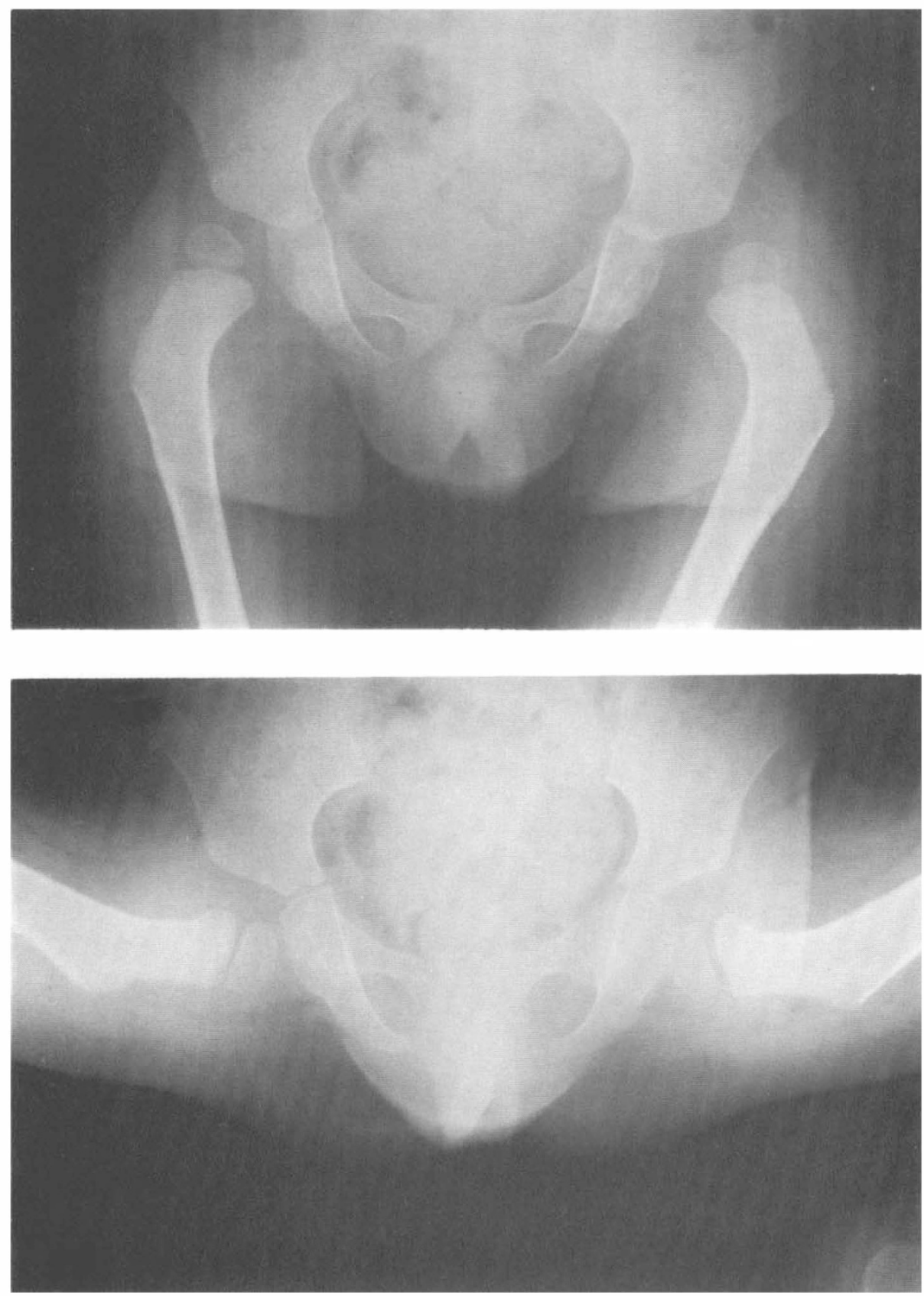

Figure 1A Radiographs showing the hip joints dislocated by passive adduction and extension. B Bilateral dislocatable hip joints were reduced easily by passive abduction and flexion. 

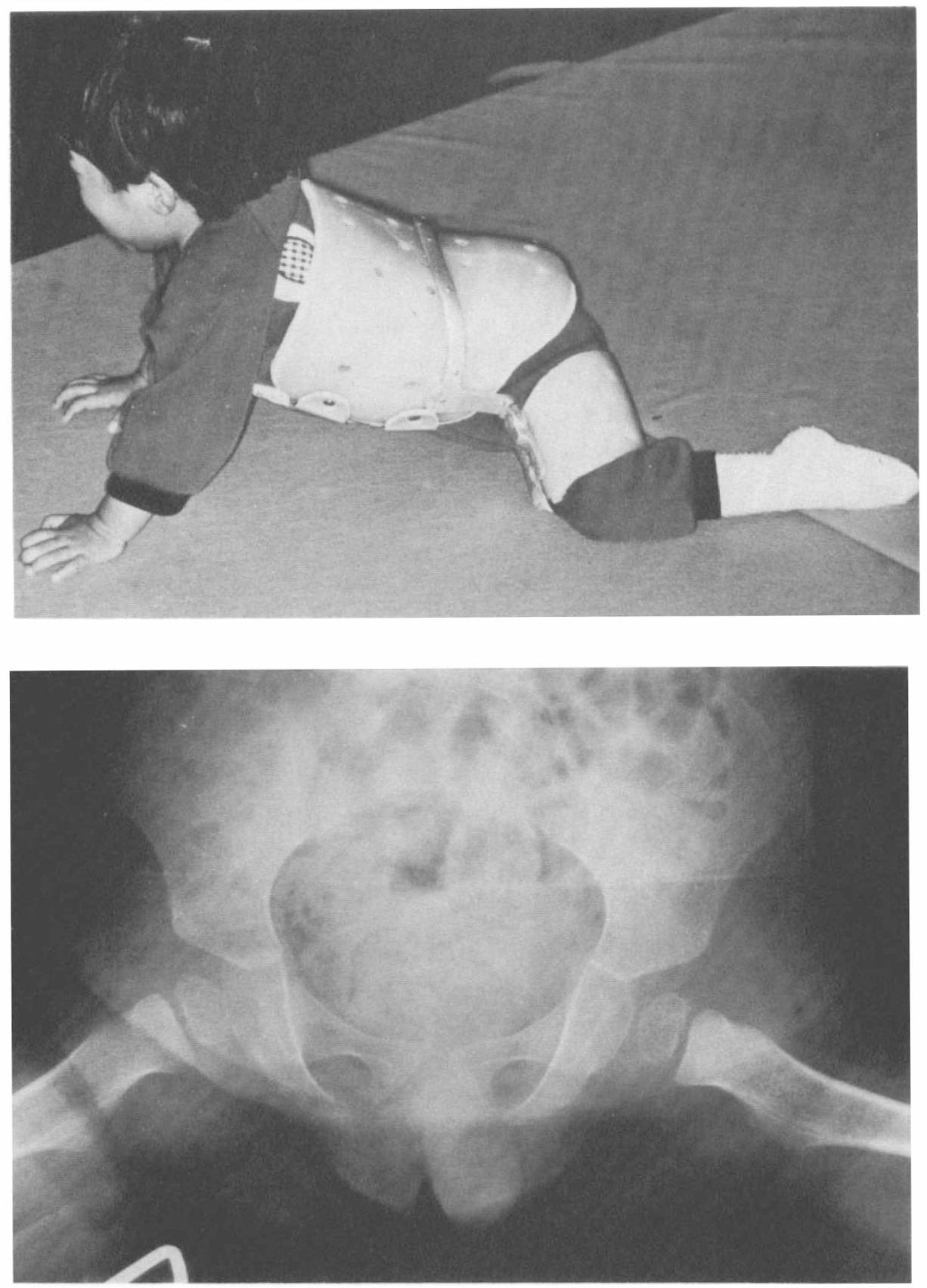

Figure 2 Hip abduction brace worn by the patient. A He could crawl by using upper limbs but not advance on his knees because of complete paralysis of lower limbs. B The hip joints were reduced by the brace. 
by using his upper limbs, he could not advance on his knees because the hip flexors were also completely paralysed. It was recommended that the brace be worn about 18 hours per day. 1 year later, the hip joints became stable.

\section{Discussion}

Kim et al. (1988) described 25 patients with non-traumatic ischaemic myelopathy. Nine of the 25 cases developed the condition following surgical manipulation of, or traumatic laceration of the aorta. Eight of these 9 patients had a flaccid paralysis. In 5 of these 8 the flaccid paralysis was complete. The authors pointed out that acute spinal cord ischaemia is due to generalised impairment of perfusion, which preferentially damages grey matter and is associated with a flaccid paralysis. Our patient also showed that complete flaccid paralysis can be a result of aortic surgery. In this case, the grey matter must be damaged and results in flaccid paralysis like lower motor neuron type of paralysis although MRI did not reveal any specific findings. MRI may not be useful in the diagnosis of ischaemic type of myelopathy.

Flaccidly paralysed musculature around the hip joints and immature bony structures of the infant hip joints were the causes of instability. Therefore the hip joints were also easily reduced. The abduction brace has to be used at least until the hip joints mature and become stable. The abduction bracing of such paralytic instability of the hip joint is thought to be effective (Raycroft, 1987).

\section{Acknowledgment}

The authors wish to thank Dr H. Aoki, a cardiac surgeon of the Asahikawa City Hospital for his help, and $\mathrm{Mr}$ Sinex for advice with language.

\section{References}

Baird RA, DeBenedetti MJ, Eltorai I 1986 Non-septic hip instability in the chronic spinal injury patient. Paraplegia 24:293-300.

BREWER LA, Fosburg RG, Mulder GA, Verska JJ 1972 Spinal cord complications following surgery for coarctation of the aorta. Fournal of Thoracic and Cardiovascular Surgery 64:368-381.

KIM SW, KIM RC, CHOI BH, GORDON SK 1988 Non-traumatic ischaemic myelopathy: a review of 25 cases. Paraplegia 26:262-272.

Pennington DG, LiberThSON RR, JaCOBS M, et al. 1979 Critical review of experience with surgical repair of coarctation of the aorta. Fournal of Thoracic and Cardiovascular Surgery 77:217-229.

RAYCROFT JF 1987 Abduction splinting of the hip joints in myelodysplastic infants. Fournal of Pediatric Orthopedics 7:686-689. 